\title{
Multidisciplinary Simulation for Gust Load Alleviation Control Surface Analysis
}

\author{
A.-R. Hübner ${ }^{1}$ and L. Reimer ${ }^{1}$ \\ andreas.huebner@dlr.de; lars.reimer@dlr.de \\ ${ }^{1}$ DLR (German Aerospace Center), \\ Institute of Aerodynamics and Flow Technology \\ Lilienthalplatz 7, 38108 Braunschweig, Germany
}

\begin{abstract}
The structural dimensioning of an airplane will be significantly influenced by gust, maneuver and ground loads. Adaptive load alleviations methods (keyword: 1g-wing) promise the potential reducing the maximum loads and therefore the structural weight. For the appropriate analysis of such load alleviation technologies a multidisciplinary approach is necessary. In order to achieve this objective a process chain for gust encounter simulation is applied using high fidelity methods for the disciplines aerodynamics, structural dynamics and flight mechanics, which are coupled in the time domain. Within multidisciplinary simulations of a generic transport aircraft configuration with and without aileron deflections the influence of vertical gusts on the resultant forces, moments, load distributions on the wing and on the horizontal tail plane are presented.
\end{abstract}

Keywords: Gust simulation, coupled CFD-CSM-FD simulations, load alleviation, multidisciplinary, numerical analysis

\section{Introduction}

Within the preliminary design process the load analysis has an important contribution, because gust and maneuver loads are significant for the structured layout. The application of adaptive load alleviation methods promise to reduce the maximum loads and therefore the structural weight.

For the prediction of the aerodynamic loads the monodisciplinary approaches are not sufficient. Due to the coupled numerical simulation of interacting disciplines the adequate accuracy for approval load cases according to CS-25 can be reached. This multidisciplinary approach is applied for the time depending gust encounter simulation taking the aerodynamic (CFD), the structural dynamic (CSD) and the flight mechanic (6DOF) behavior into account.

In addition to the analysis of the natural frequencies of a common gust encounter simulation different functions for the aileron deflections are compared with the configuration without aileron deflection within the multidisciplinary simulations in order 
to determine the impact on the resultant forces, moments, load distributions of the wing and the horizontal tail plane.

\section{$2 \quad$ Numerical methods}

For the simulation of unsteady gust interaction calculations a multidisciplinary process chain is used, which was developed within the DLR project Digital-X [1]. In the process chain, highly precise methods for the disciplines aerodynamics, dynamics of elastic structure deformation and rigid body dynamics are coupled with each other in the time domain. The process chain is implemented in the DLR-FlowSimulator software environment [2], which supports massively parallel applications.

Gust encounter simulations are performed for the generic transport aircraft for cruise conditions with and without deflected ailerons.

\subsection{CFD computational models}

The examined generic transport aircraft consists of fuselage, wing with ailerons, flap track fairings, pylons and flow-through nacelles as well as horizontal and vertical tail plane (see Fig. 1). For the calculations the RANS method DLR-TAU is applied [3] using unstructured, hybrid grids generated with the mesh generator CENTAUR by CentaurSoft[4]. A coarse grid with $10 \times 10^{6}$ grid points is used to test the process chain functionalities and for qualitative investigations. A finer grid with $27 \times 10^{6}$ grid points is used for quantitative analysis.

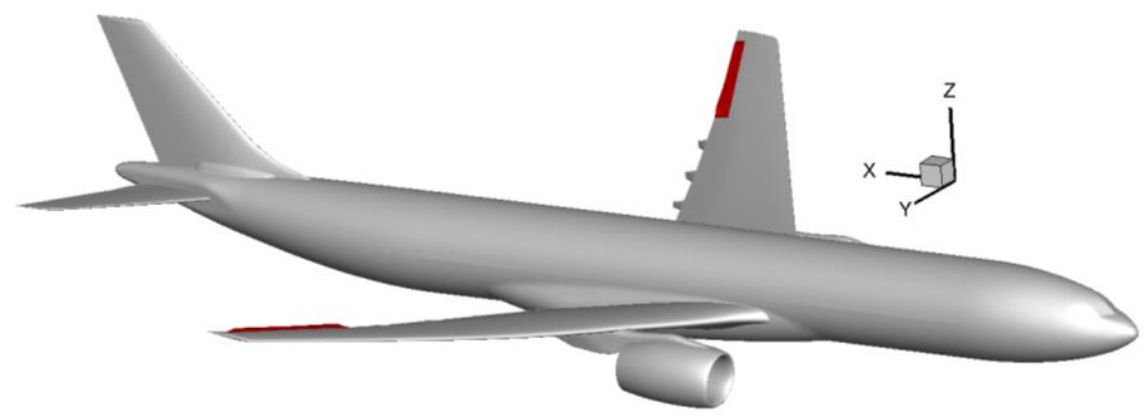

Fig. 1. Surface model of the generic transport aircraft with deflected ailerons (red)

\subsection{Structure and coupling model}

A condensed FEM model for dynamic analysis (a so-called Dynamic Master Model) is used which was created by the DLR Institute of Aeroelasticity. Fig. 2 shows the condensed structure model - the A-Set nodes, which in their entirety form the socalled load reference axis (LRA). The model is designed as a "free-free" model and is therefore statically indeterminate. 


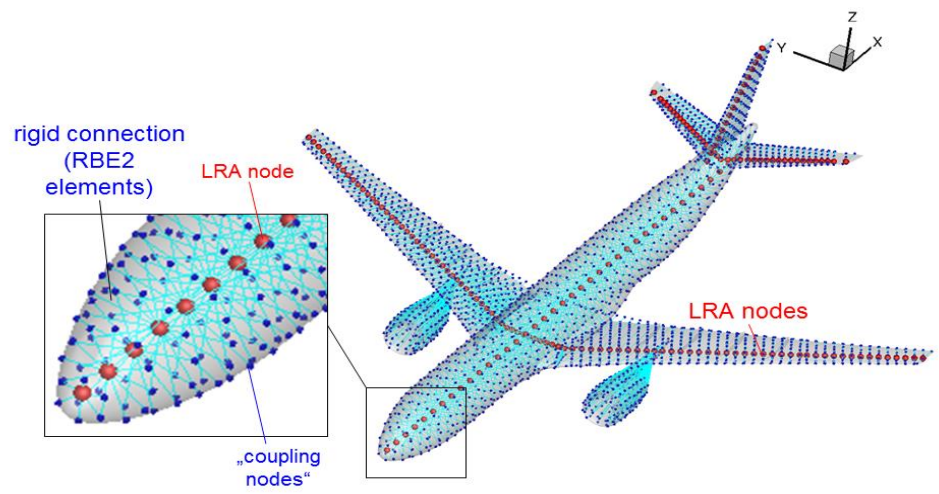

Fig. 2. Structural model (including additional nodes for CFD-CSD coupling = "coupling model")

Inertia properties resulting from structure, secondary systems, fuel and payload distribution are described in the model as concentrated mass points (NASTRAN COMN2 elements).

To solve the structural dynamics problem, a modal method is used. 44 elastic eigenmodes of the structure are used in the coupled simulations. They are calculated within a preprocessing using NASTRAN SOL103.

As part of the load and deformation transfer between CFD surface and structure, an extended structural model is used. Additional structural nodes - so-called coupling points - are distributed on the CFD surface and rigidly connected to the LRA nodes by RBE2 elements, which represent the elastic structure (see Fig. 2).

\subsection{Process chain}

For the gust encounter simulation, the basic tool used is the DLR RANS solver TAU for providing the aerodynamic data. It also provides the opportunity to simulate gusts in various forms [5].

If the aircraft's flight dynamics response and elastic behavior are to be taken into account in the gust encounter simulation, TAU is coupled with a modal method for solving the linearized rigid body motion equations and a modal structural dynamics solver. The multidisciplinary process chain used is shown in Fig. 3 [6].

For load and deformation interpolation between aerodynamic surface and structure, a thin-plate spline is applied. It is generated between the points of the CFD surface mesh and the coupling points of the structural model [2]. The deformation transferred to the CFD surface is propagated into the CFD volume grid using RBF-based mesh deformation (a volume spline is used).

The CFD-CSD coupling process with coupled grid deformation routine also applies to the trim calculation necessary for every gust simulation to determine the steady state, undisturbed horizontal flight of the elastic aircraft. Here, the three degrees of freedom are iteratively adjusted within the trimming algorithm: pitch angle $\theta$, 
horizontal tail plane setting angle $\eta$ and engine thrust setting $t$, until the resultant forces and moments around the center of gravity of the aircraft become zero.

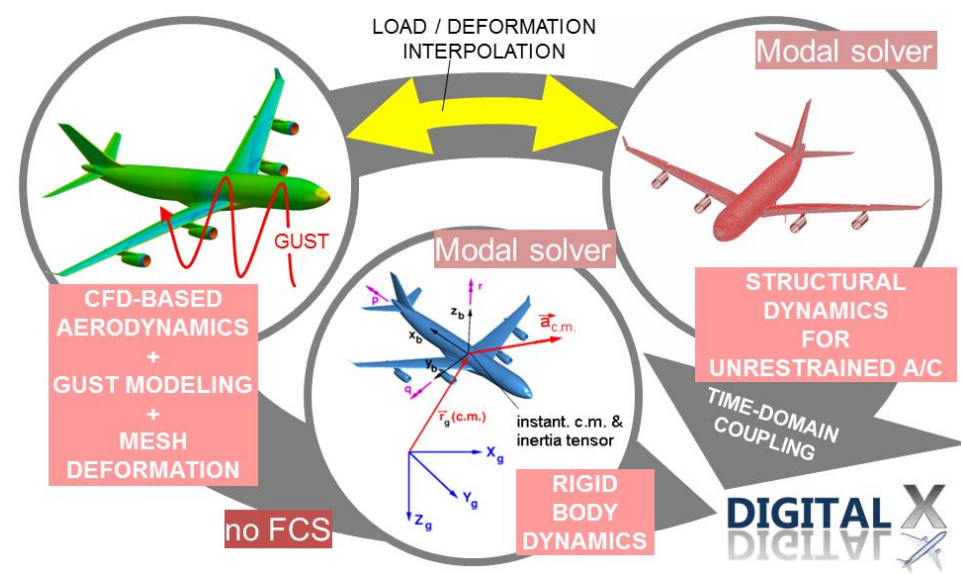

Fig. 3. Multidisciplinary process chain from the project Digital X (HAP 5)

Due to the grid deformation, the horizontal tail plane adjustment in the area of the fuselage intersection is adapted. As an example, Fig. 4 shows the deformation of the aircraft in the trimmed state for the examined flight condition.

So far, no flight control system (FCS) has been introduced into the process chain. Controlled surface deflections requirements can therefore be taken into account by manual specification of the time-dependent aileron deflection.

In gust encounter calculation, an additional velocity field - e.g. for a vertical or lateral gust - is taken into account in the flow simulation [7][8].

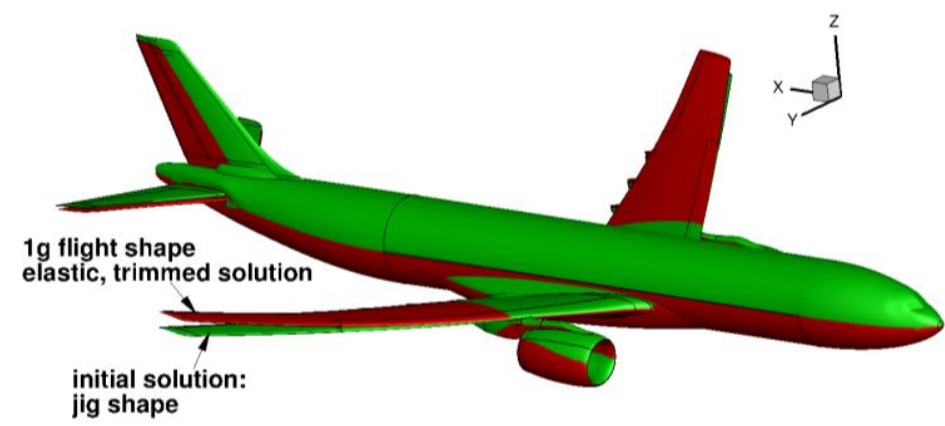

Fig. 4. Deformation of the generic aircraft configuration for the trimmed state flight level 


\section{$3 \quad$ Numerical results}

\subsection{General description of the gust characteristic}

The numerical simulations were performed in the transonic flight range at FL350. According to CS-25, the investigated gust has a wavelength of $\lambda=100 \mathrm{~m}$ and an amplitude of $\widehat{U}_{\text {gust }}=10 \mathrm{~m} / \mathrm{s}$. However, the vertical gust moves at a speed of $175 \mathrm{~m} / \mathrm{s}$. Some further basic investigations with the configuration without control surfaces are described in [9]. Fig. 5 shows an example of a flight of the generic aircraft configuration through a vertical "1-cos"-gust shape. An acceleration of approx. 1.6g is achieved.

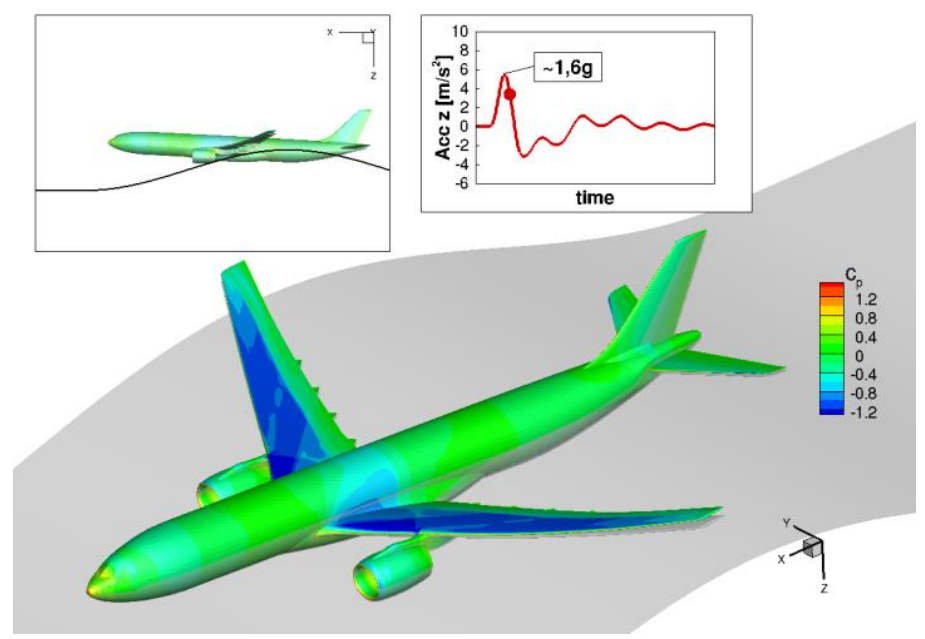

Fig. 5. Example of an unsteady gust simulation

The time-dependent lift and pitching moment coefficients of the full coupled CFDCSM-FD simulation are compared in Fig. 6. The starting point is the trimmed elastic configuration at $\mathrm{t}=0 \mathrm{~s}$. The area marked in gray indicates the beginning influence of the maximum gust amplitude of $\widehat{U}_{\text {gust }}=10 \mathrm{~m} / \mathrm{s}$ on the fuselage nose $(\mathrm{t}=41 \mathrm{~s})$ and finally on the rear fuselage $(t=77 \mathrm{~s})$. At time $t=0.57 \mathrm{~s}$, the maximum gust velocity reaches the moment reference point.

The amplitudes resulting from the frequency analysis for $C_{L}$ and $C_{m y}$ are also described in Fig. 6. In the pitching moment characteristic obvious peaks at $\mathrm{f}=1.3 \mathrm{~Hz}$ and $\mathrm{f}=4.7 \mathrm{~Hz}$ are shown and an additional peak at $\mathrm{f}=2,6 \mathrm{~Hz}$ in the lift distributions. At $\mathrm{f}=1.3 \mathrm{~Hz}$, a structural mode due to the bending-torsional coupled deformation of the wing is excited. The analysis of the time-dependent displacement in z-direction and the rotation around the $y$-axis of an airfoil section in the wing outer area at $\eta=$ 0.88 , which correspond to the bending and the twist of the wing confirms this 
behavior (see Fig.7). The Fourier analysis confirms an eigenform at $\mathrm{f}=1.3 \mathrm{~Hz}$. The analysis of the structural eigenmodes also shows that the peak at $\mathrm{f}=2.6 \mathrm{~Hz}$ and $\mathrm{f}=$ $4.7 \mathrm{~Hz}$ probably result from a horizontal tail plane bending and a nacelle-pylon-wing interaction.
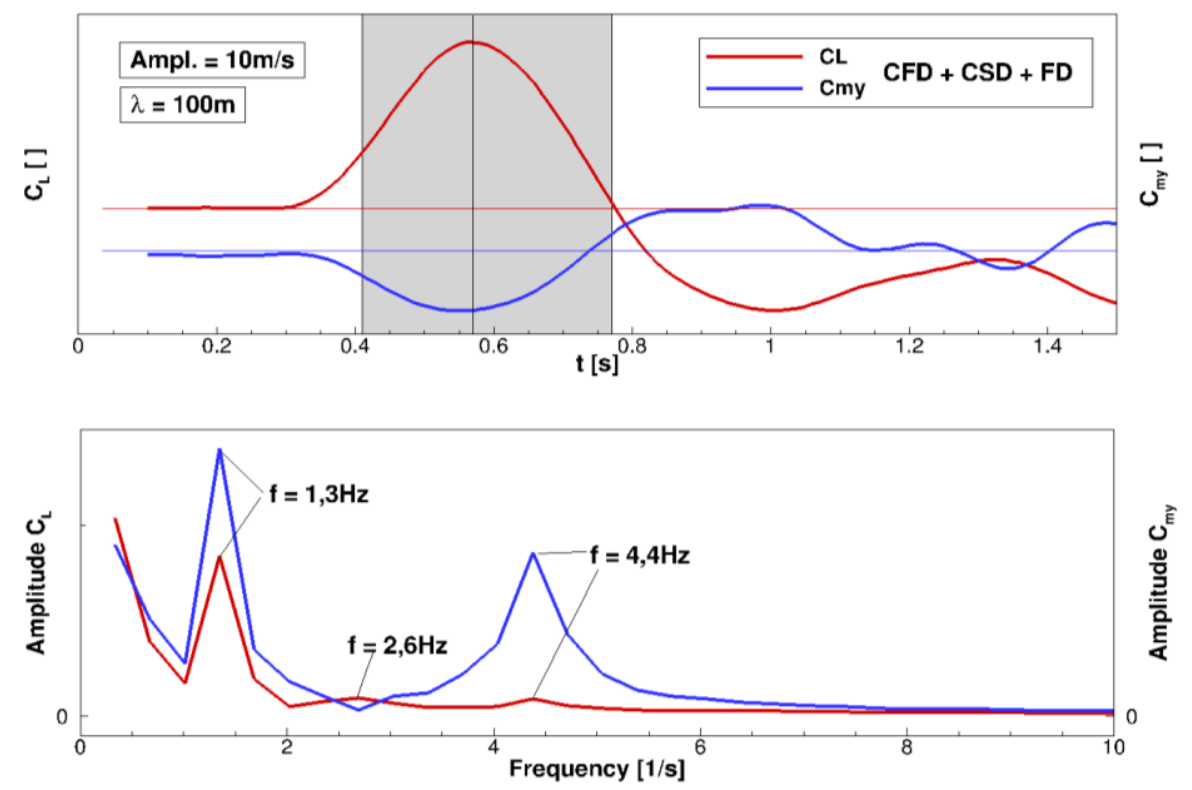

Fig. 6. Analysis of the lift and pitching moment coefficients of the full coupled CFD-CSM-FD simulation

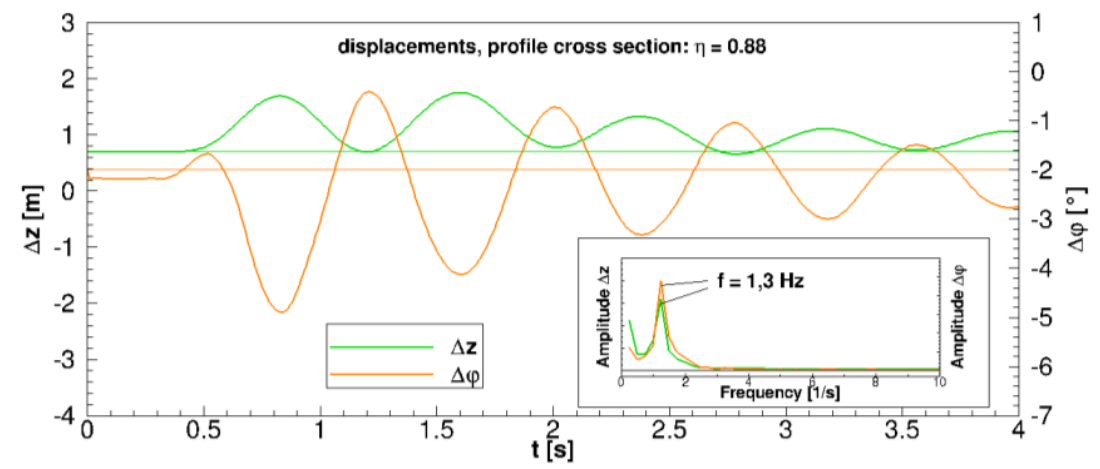

Fig. 7. Displacement in z-direction and rotation around the y-axis of a wing airfoil section at $\eta=0.88$ 


\subsection{Influence of aileron deflections}

By manual specification of the time-dependent control surface deflection it is possible to take the aileron deflections into account. In this case, only equal flap deflections on the right and left hand side of the wing are specified.

In Fig. 8 three feasible flap deflection paths are exemplified. This includes the flap deflection using a ramp function. The extension can be done either within a time step (red) or several time steps. In the second case, the flap is retracted again after a predefined time (green). These are compared to a "1-cos"-function deflected flap (blue).

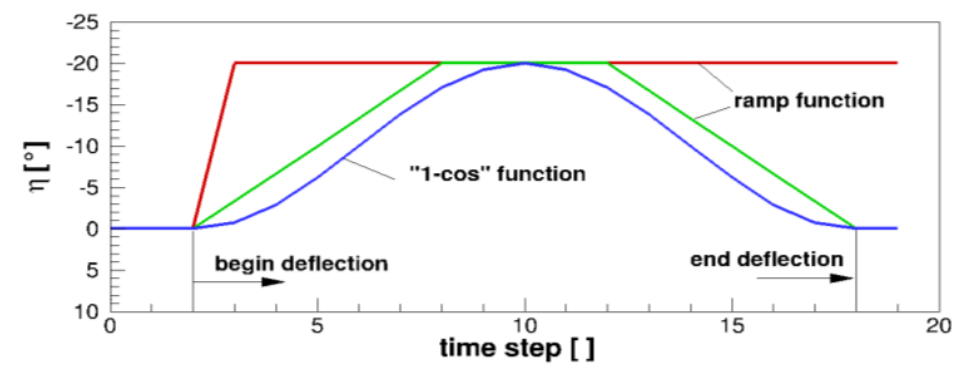

Fig. 8. Different flap deflection paths of an aileron

Fig. 9 shows the comparison of the lift and the pitching moment curves in case of gust encounter simulation of a configuration without aileron deflection to a deflected aileron of $\eta=-20^{\circ}$ that has been extended at a time $\mathrm{t}=0.5 \mathrm{~s}$ over a time step $\Delta \mathrm{t}=$ $0.01 \mathrm{~s}$. Within this time step the aerodynamic behavior reacts completely to the changed flap setting. Depending on the starting point of the extension, the total lift can thus be reduced during the gust simulation. However, the pitching moment is also affected at the same time, which makes it necessary to control the pitch angle of the aircraft during and after the gust interaction.

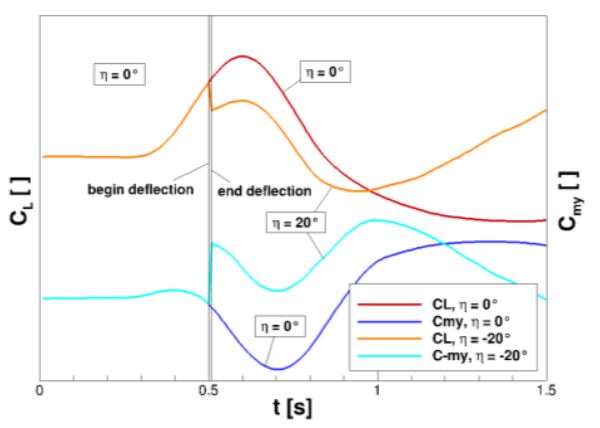

Fig. 9. Comparison of lift and pitching moment curves of a configuration without and with aileron deflection (one time step function)

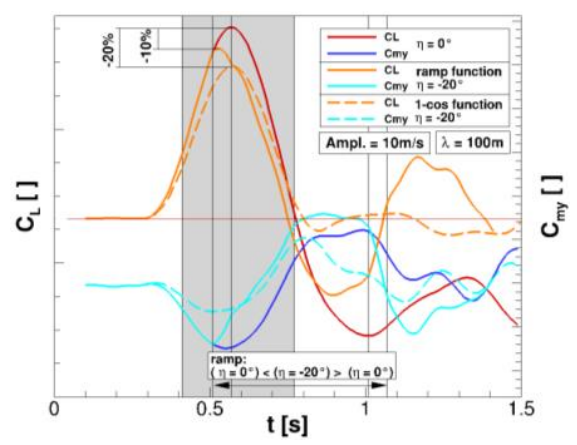

Fig. 10. Comparison of lift and pitching moment curves of a configuration without and with different aileron deflections 
If the aileron is extended at a lower speed and retracted at a later date $t=1,07 \mathrm{~s}$ (see Fig. 10), the maximum and minimum aerodynamic responses are reduced, especially in lift characteristic of $-10 \%$. The deflection of the aileron with a "1-cos"-function at the same flap angle of $\eta=-20^{\circ}$ leads to a $20 \%$ reduced lift increase. Even after the maximum vertical gust speed has left the fuselage rear end downstream, the disturbances in the lift and in the pitching moment behavior are small. However, the aerostructure coupled reactions are not negligible.

The associated force and moment distributions over the wingspan confirm these results. Corresponding to the flap deflection paths in Fig. 10, the respective maximum spanwise $\Delta \mathrm{Fz}$ force components of the wing and of the horizontal tail plane relative to the trimmed solution at $\mathrm{t}=0 \mathrm{~s}$ are shown in Fig. 11a. The pitching moment curves are compared in Fig. $11 \mathrm{~b}$.

The comparisons of the results getting with the ramp function for the aileron deflection to the wing without flap deflection $\left(\eta=0^{\circ}\right)$ show a significant reduction of the Z-force component in the area of the aileron and also a slight decrease in the wing inboard area. However, the biggest effects in terms of load reduction are achieved using the "1-cos" function for the aileron deflection.
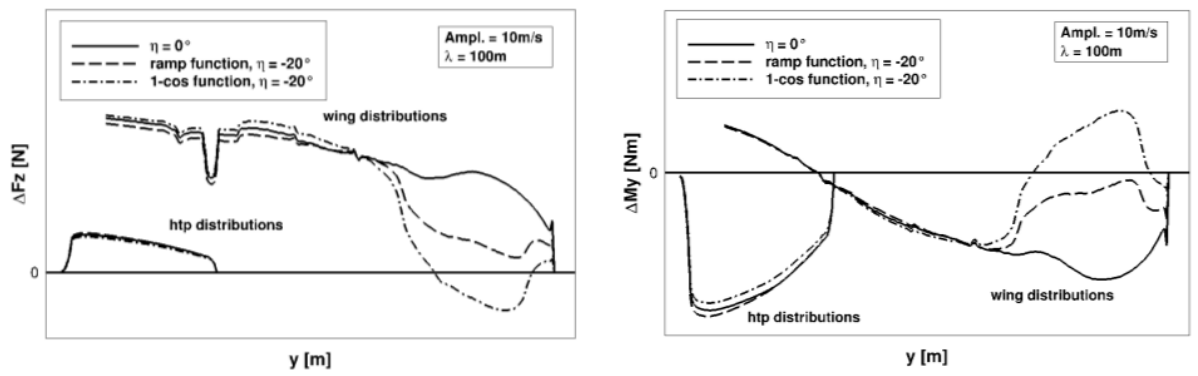

Fig. 11. Maximum force (a) and moment (b) distributions over the wing and the horizontal tail plane using different aileron deflection paths

\section{$4 \quad$ Summary and Outlook}

For unsteady gust encounter simulations, a multidisciplinary process chain is used, which takes the aerodynamic (CFD), structural-dynamic (CSM) and flight mechanic (6DOF) characteristics of an aircraft into account.

Within the simulations different functions for the aileron deflections are compared with the configuration without aileron deflections in order to determine the impact on the resultant forces and moments and the load distributions of the wing and the horizontal tail plane. It can be shown in one case that a load reduction of $20 \%$ is achieved using the "1-cos" function for the aileron deflection. Further investigations have to be done in order to understand the interactions between the influence of the gust onto the 
aerodynamic behavior of the aircraft and the time dependent controlled reaction of the ailerons deflections. Furthermore additional control surfaces (elevator, rudder, spoiler) have to be taken into account in the gust encounter simulations to get a better understanding of the coupled aerodynamic, structural and flight mechanic behavior.

\section{$5 \quad$ Acknowledgment}

For the simulations of multidisciplinary gust encounter calculations, a process chain was used, which was developed within the DLR project Digital-X. The authors would like to thank Markus Ritter of the DLR Institute for Aeroelasticity, who was responsible for the development of this process chain.

\section{References}

1. Kroll, N. et al.: DLR-Projekt Digital-X, Auf dem Weg zur virtuellen Flugzeugentwicklung und Flugerprobung auf Basis höherwertiger Verfahren, Deutscher Luft- und Raumfahrtkongress, DLRK2014-340099, 16.-18. September, Augsburg (2014).

2. Reimer, L. et al.: CFD-based Gust Load Analysis for a Free-flying Flexible Passenger Aircraft in Comparison to a DLM-based Approach. AIAA Aviation 2015, June 22-26, Dallas TX, USA (2015).

3. Schwamborn, D., Gerhold, T., Heinrich, R.: The DLR TAU Code: Recent Applications in Research and Industry. In proceedings of European Conference on Computational Fluid Dynamics, ECCOMAS CDF 2006, Delft, The Netherland (2006).

4. CENTAURSOFT, http://centaursoft.com.

5. DLR TAU code, http://tau.dlr.de.

6. Ritter, M.: Nonlinear Numerical Flight Dynamics of Flexible Aircraft in the Time Domain by Coupling of CFD, Flight Mechanics and Structural Mechanics, New Results in Numerical and Experimental Fluid Mechanics VIII, Springer-Verlag, Vol. 121, 2010, p339-347.

7. Heinrich, R.: Simulation of Interaction of Aircraft and Gust Using the TAU-Code, in Dillmann, A. et al.: New Results in Numerical and Experimental Fluid Mechanics IX, Notes on Numerical Fluid Mechanics and Multidisciplinary Design, Springer-Verlag, Vol. 124, pp. 503-511 (2014).

8. Heinrich, R., Reimer, L.: Comparison of different approaches for gust modeling in the CFD Code TAU, International Forum on Aeroelasticity and Structural Dynamics, 2427June, Bristol, UK (2013).

9. Hübner, A., Reimer, L.: Multidisziplinäre Böensimulation zur Lastabminderungsanalyse, Deutscher Luft- und Raumfahrtkongress, DLRK2018-0044, 04.-06. September, Friedrichshafen (2018). 